\title{
Nghiên cứu thiết lập phương pháp cơ bản đánh giá rủi ro lũ lụt ở đồng bằng sông Cửu Long
}

\author{
Cấn Thu Văn ${ }^{1, *}$, Nguyễn Thanh Sơn ${ }^{2}$ \\ ${ }^{1}$ Truờng Đại học Tài nguyên và Môi truờng TP. Hồ Chí Minh, 236B Lê Văn Sỹ, Tân Bình, TP. HCM \\ ${ }^{2}$ Truờng Đại học Khoa học Tụ nhiên, ĐHQGHN, 334 Nguyễn Trãi, Thanh Xuân, Hà Nội, Việt Nam
}

Nhận ngày 08 tháng 8 năm 2016

Chỉnh sửa ngày 26 tháng 8 năm 2016; Chấp nhận đăng ngày 16 tháng 12 năm 2016

\begin{abstract}
Tóm tắt: Hiện nay, phần lớn các nghiên cứu về rủi ro lũ lụt đều xác định rủi ro là hàm số của ba thành phần: hiểm họa; độ phơi nhiễm và tính dễ bị tổn thương xã hội. Đánh giá rủi ro lũ lụt ngoài việc cung cấp các ước tính thiệt hại về người và tài sản còn đề ra các biện pháp nhằm giảm thiểu rủi ro thiên tai bằng việc xem xét năng lực của từng hộ gia đình để thích nghi và ứng phó khi lũ xuất hiện. Tuy nhiên không thể dùng chung một phương pháp và các biện pháp giảm thiểu cho các vùng khác nhau, mỗi vùng có đặc tính lũ khác nhau, điều kiện kinh tế-xã hội khác nhau gây ra tính dễ bị tổn thương và khả năng chống chịu hoàn toàn khác nhau. Vì vậy, ứng với một vùng cụ thể cần thiết phải xác lập một phương pháp tính toán sao cho phù hợp nhất đảm bảo đề xuất được các biện pháp giảm thiểu có hiệu quả. Đặc biệt lũ lụt ở đồng bằng sông Cửu Long (ĐBSCL) có những tính chất khác hẳn so với các vùng khác ở phía Bắc hay miền Trung đã được công bố ở các nghiên cứu trước đây, vì vậy nghiên cứu này sẽ phân tích và thiết lập phương pháp đánh giá rủi ro do lũ lụt phù hợp cho vùng ĐBSCL.
\end{abstract}

Tù khóa: Lũ lụt, Rủi ro, ĐBSCL.

\section{Tổng quan về đánh giá rủi ro thiên tai lũ lụt}

Thiên tai và những tác động đến kinh tế, xã hội ngày càng gia tăng trên toàn thế giới với một tốc độ rất đáng báo động. Con người, tài sản, xã hội và môi trường đang bị ảnh hưởng rất nhiều từ các hiểm họa tự nhiên. Bất kỳ sự thay đổi nào về mặt xã hội như: sự tăng dân số, tăng trưởng kinh tế, đô thị hóa, công nghiệp hóa, phá rừng, mở rộng khu dân cư, di canh, di cư... làm cho xã hội dễ bị tổn thương bởi các hiểm họa tự nhiên. Số người bị ảnh hưởng bởi thiên tai trung bình 147 triệu người từ năm 1981-1990 và con số này tăng lên 221 triệu người cho thập kỷ tiếp theo 1991-2000. 2/3 trong số này là ảnh

Tác giả liên hệ. ĐT.: 84-983738347

Email: canthuvantrh@gmail.com hưởng bởi lũ lụt và $1 / 3$ thiệt hại về kinh tế. Một cách tiếp cận tổng hợp là rất quan trọng trong việc bảo vệ và quản lý lũ, việc nghiên cứu các hiểm họa lũ và tính dễ bị tổn thương nên được định hướng tới các hoạt động thích ứng $[1,2]$.

Biến đổi khí hậu được dự báo sẽ làm tăng tần suất và mức độ nghiêm trọng của các hiện tượng thời tiết cực đoan. Kết quả là những thiệt hại về kinh tế gây ra bởi các hiểm họa tự nhiên có thể tăng lên một cách đáng kể. Với quá trình đô thị hóa nhanh chóng trong điều kiện biến đổi khí hậu, thiên tai lũ lụt ngày càng gia tăng sẽ đe dọa đến sự phát triển bền vững vì vậy cách tiếp cận quản lý tổng hợp lũ là cần thiết. Quản lý tổng hợp lũ sẽ cho thấy sự tương quan giữa các biện pháp quản lý rủi ro, các phân tích đánh giá, chi phí, tính hiệu quả và vai trò của các yếu tố 
này trong điều kiện thay đổi kinh tế, xã hội và môi trường. Các khu đô thị được mở rộng, ngày càng kiên cố và sự thay đổi dân cư trong vùng đồng bằng ngập lũ, sự thay đổi đặc trưng lũ theo sự phát triển của lưu vực trong điều kiện biến đổi khí hậu, tất cả các hành động làm tăng sự tiếp xúc của cộng đồng với nguy cơ rủi ro lũ. Nếu không có một cách quản lý hiệu quả nguy cơ rủi ro lũ lụt, quy mô tác động của lũ lụt đối với con người, tài sản, công nghiệp và kinh tế sẽ ngày càng gia tăng.

Nguy cơ lũ lụt là khả năng xảy ra những thiệt hại tiềm năng do lũ với một cường độ nhất định trong một vùng nhất định ở một thời điểm nhất định. Một số các yếu tố (hoặc các tham số) gây ra những thiệt hại tiềm năng do hiểm họa lũ lụt. Các tham số này có thể được định lượng thông qua các chỉ số như: độ sâu ngập lụt, thời gian ngập lụt, vận tốc, tỷ lệ tăng lên của mực nước biển, tần xuất xuất hiện. Tất cả các nhân tố này và các chỉ số có mối quan hệ phức tạp và tác động khác nhau $[1,3]$.

Sự gia tăng dân số và mức sống của người dân ngày càng cao với việc sử dụng các đồ dùng gia đình có giá trị đã làm tăng tính dễ bị tổn thương của xã hội đối với các hiểm họa lũ lụt. Sự phát triển này đã tạo ra những thách thức mới cho xã hội và môi trường. Sự phát triển kinh tế và mức sống người dân ngày càng cao đòi hỏi một môi trường ngày càng an toàn. Tuy nhiên, có sự xung đột là trong khi công nghiệp hoá, hiện đại hoá và sức mạnh chi tiêu sẽ sử dụng nhiều sản phẩm, kéo theo là việc để lại đằng sau số lượng lớn các chất thải cần được xử lý đúng cách. Vì vậy, để phát triển một phạm vi rộng để đánh giá tính dễ tổn thương liên quan đến khía cạnh kinh tế, xã hội, và môi trường là cần thiết [4].

Hầu hết những nghiên cứu đánh giá rủi ro lũ lụt, các tham số rủi ro đã được thẩm định một cách riêng biệt và số lượng các tham số cũng được giới hạn. Việc số lượng các trận lũ ngày càng tăng và nước biển dâng do nóng lên toàn cầu, biến đổi khí hậu và sự thay đổi môi trường cũng được tính đến một cách thích hợp. Để có được những tham số này thì các nghiên cứu phải được tiếp cận theo hướng quản lý tổng hợp rủi ro lũ lụt trong vùng đồng bằng ngập lũ. Số lượng các tham số có liên quan tới các khía cạnh: hiểm họa lũ, kinh tế, xã hội và môi trường theo sự phân bố có trọng số của rủi ro lũ. Bên cạnh đó thì đặc trưng tần suất, cường suất lũ, sự thay đổi của mực nước biển coi như tham số tính nhạy đối với đánh giá tương lai.

Đã có nhiều hướng nghiên cứu khác nhau về rủi ro, nhằm phân loại các thành phần, yếu tố để đánh giá. Tuy nhiên, việc sử dụng các thuật ngữ liên quan đến rủi ro giữa các ngành, lĩnh vực nghiên cứu vẫn còn nhiều tranh cãi trong các cộng đồng, các hướng nghiên cứu khoa học khác nhau. Các nhà nghiên cứu trong lĩnh vực khoa học tự nhiên thường chú trọng vào khái niệm rủi ro (risk) trong khi các nhà nghiên cứu trong lĩnh vực khoa học xã hội thường nhắc đến thuật ngữ tính dễ bị tổn thương (vulnerability). Khái niệm rủi ro lũ lụt được cho là mức độ nguy hiểm của tai biến lũ lụt hay rủi ro là các thiệt hại ngẫu nhiên của tai biến lũ lụt. Sự phát triển của việc phân tích tai biến lũ lụt đã được nghiên cứu song song với đánh giá thiệt hại lũ lụt. Trong vài thập kỷ qua, phân tích lũ lụt tập trung chủ yếu vào các đại lượng vật lý (lượng ngập, diện tích ngập, độ sâu ngập lụt,...) và thiệt hại trực tiếp của các thành phần kinh tế do lũ lụt gây ra. Tuy nhiên, trong những năm gần đây phân tích rủi ro lũ lụt cũng đã đề cập đến rủi ro môi trường - xã hội theo hướng tiếp cận quản lý tổng hợp lũ [5].

Rủi ro lũ lụt được coi là các sản phẩm ngẫu nhiên của nguy cơ và tiềm năng tổn thất của nó. Trong vài thập kỷ qua, lũ lụt phân tích tập trung chủ yếu vào kích thước vật lý của lũ lụt (lượng, diện tích, độ sâu ...) và thiệt hại trực tiếp của các thành phần kinh tế. Tuy nhiên, trong những năm gần đây phân tích rủi ro lũ lụt cũng đã phân tích đến rủi ro môi trường - xã hội - đó là hướng tiếp cận quản lý tổng hợp lũ. ADRC (2005) (Asian Disaster Reduction Center) cho rằng rủi ro là giá trị của thiệt hại như là: tính mạng, thương, tài sản... bị ảnh hưởng bởi hiểm họa. Theo hướng tiếp cận này, gần đây, nhóm tác giả $E$. Koks và cộng sự đã đánh giá rủi ro lũ lụt bằng việc kết hợp giữa ba thành phần là hiểm họa lũ lụt, độ phơi nhiễm và tính dễ bị tổn 
thương xã hội, nghiên cứu cho rằng ngoài việc cung cấp các ược tính thiệt hại về người và tài sản thì để đề ra các biện pháp nhằm giảm thiểu rủi ro lũ lụt còn phụ thuộc vào năng lực của từng hộ gia đình để thích nghi và ứng phó với lũ lụt, vì vậy cần thiết phải xem xét đến tính dễ bị tổn thương xã hội do lũ lụt của khu vực nghiên cứu $[3,5]$.

Qua đó thấy rằng, các nghiên cứu đã tiếp cận theo hướng tổng hợp, tích hợp các thành phần vật lý, kinh tế, xã hội, môi trường... các nghiên cứu đều nhận định rằng đánh giá rủi ro lũ lụt tổng hợp là cần thiết để quản lý lũ. Tuy nhiên không thể dùng chung một phương pháp và các biện pháp giảm thiểu cho các vùng khác nhau, mỗi vùng có đặc tính lũ khác nhau, điều kiện kinh tế-xã hội khác nhau gây ra tính dễ bị tổn thương và khả năng chống chịu hoàn toàn khác nhau. Vì vậy, ứng với một vùng cụ thể cần thiết phải xác lập một phương pháp tính toán sao cho phù hợp nhất đảm bảo đáp ứng từng phần với tình hình đặc trưng của từng vùng cụ thể.

\section{Xây dựng phương pháp cơ bản đánh gía rủi ro lũ lụt vùng đồng bằng sông Cửu Long}

Bản chất của rủi ro lũ lụt là ngẫu nhiên và việc xác định rủi ro lũ là rất đa dạng. Vì vậy rất khó khăn để định lượng rủi ro lũ lụt khi coi rủi ro là hệ quả của một hiện tượng tự nhiên có tác động đến con người bao gồm: cuộc sống, tài sản và khả năng chống chịu với hiểm họa. Rủi ro chỉ xảy ra khi hiểm họa tự nhiên và những lo lắng của con người cùng xảy ra, nếu không thì không có rủi ro. Rủi ro lũ lụt được định nghĩa là mức độ tác động bất lợi tổng thể của lũ lụt. Thuật ngữ "rủi ro lũ" kết hợp các khái niệm của sự đe dọa cho cuộc sống, sự khó khăn và nguy hiểm cho việc sơ tán người và tài sản khi có lũ lụt, những thiệt hại tiềm năng về cấu trúc và giá trị ngôi nhà, gián đoạn xã hội, tổn thất hoa màu, phá hủy các công trình công cộng. Rủi ro là hàm của hiểm họa (Hazard), tính dễ bị tổn thương xã hội (Vulnerability) và độ phơi nhiễm (Exposure), Risk $=f(H, V, E)$.
Cùng với khái niệm thì phương pháp đánh giá rủi ro cũng ngày càng phát triển đa dạng. Các phương pháp này có thể nhóm lại theo hai hướng đánh giá: trực tiếp - mang tính định tính và gián tiếp - mang tính định lượng (thông qua bộ chỉ số), cụ thể như: phương pháp điều tra xã hội học, phương pháp tích hợp bản đồ và phương pháp chỉ số. Mỗi phương pháp đánh giá có những ưu, nhược điểm riêng, trong nghiên cứu này sẽ làm rõ phương pháp chỉ số:

Xây dựng bộ chỉ số rủi ro lũ lụt gồm các bước: 1- Lựa chọn vùng nghiên cứu (Tìm hiểu đặc trưng lũ lụt vùng nghiên cứu); 2- Thiết lập các tiêu chí; 3- Chuẩn hóa các biến số; 4- Xác định trọng số (nếu có); 5- Tính giá trị các tiêu chí $(\mathrm{H}, \mathrm{V}, \mathrm{E})$; 6- Xác định chỉ số rủi ro và đánh giá mức độ rủi ro lũ lụt. Cụ thể các bước như sau:

\subsection{Lựa chọn và đặc điểm lũ vùng đồng bằng sông Cưu Long}

Đối với ĐBSCL, đây là khu vực có ý nghĩa đặc biệt quan trọng trong công cuộc phát triển kinh tế xã hội của cả nước và trước những biểu hiện của $\mathrm{BĐKH} \mathrm{thì} \mathrm{nơi} \mathrm{đây} \mathrm{được} \mathrm{cho} \mathrm{là} \mathrm{sẽ} \mathrm{chịu}$ ảnh hưởng nặng nề nhất và mức độ rủi ro thiên tai vì thế cũng ở mức cao. Hơn nữa nơi đây có những đặc trưng riêng đặc biệt là về lũ lụt đòi hỏi phải có nghiên cứu và đánh giá chuyên sâu mức độ rủi ro tổng hợp nhằm định hướng và xây dựng chính sách quản lý lũ lụt. Ở ĐBSCL ta quen dùng chữ "lũ lụt" đối với ĐBSCL như ở phía Bắc mà dân ở đây chỉ xem là mùa nước nổi, bởi lẽ dù là mùa nước lũ thì cường suất lũ lên chỉ khoảng $5-15 \mathrm{~cm} /$ ngày là chưa thực sự phù hợp. Thực tế cho thấy, nếu không có mùa nước nồi hàng năm thì ĐBSCL chưa chắc đã có diện mạo như ngày hôm nay vì nước nổi đã mang lại nhiều lợi ích cho đồng bằng như: phù sa, dưỡng chất, thủy sản, rủa độc, diệt sâu bọ, cải tạo môi trường... trừ phi là năm mà có nước quá lớn.

Khác hẳn với các vùng phía Bắc và miền Trung, ở ĐBSCL tồn tại một khái niệm là "lũ đẹp" khi mực nước Hmax tại Tân Châu trong khoảng $400 \mathrm{~cm}$ đến $420 \mathrm{~cm}$, vượt khỏi khoảng này $\pm 30 \mathrm{~cm}$ thì lập tức mức độ gây hại là nhiều 
hơn lợi ích mà nó mang lại. Nếu mực nước tại Tân Châu lớn hơn $450 \mathrm{~cm}$ là mực nước sẽ gây nguy hiểm về uy hiếp ngập sâu, an toàn dân cư và các thực thể kinh tế khác (trong 87 năm từ 1929-2015 chỉ có 15 năm như vậy tức trung bình cứ 5 năm lại có 1 năm Hmax lớn hơn $450 \mathrm{~cm}$ ). Ngược lại nếu mực nước Hmax tại Tân Châu thấp hơn $370 \mathrm{~cm}$ trường hợp này ở đây gọi là "đói lũ" và mức độ thiệt hại cũng không thấp hơn so với lũ lớn có $H$ max lớn hơn $450 \mathrm{~cm}$, như: nguồn nước ô nhiễm trong mùa khô không được rửa trôi, chuột bọ sinh sôi nhiều, thiếu nước trong những năm tiếp theo...(trung bình cứ 10 năm lại có 3 năm như vậy).

\subsection{Thiết lập bộ tiêu chí đánh giá rủi ro lũ lut vùng đồng bằng sông Cửu Long}

Ở $[1,5]$ cũng đã chỉ ra chi tiết cách xác định các tiêu chí đối với lưu vực sông miền Trung. Như đã trình bày, mỗi vùng có đặc trưng lũ lụt khác nhau, bộ tiêu chí với các tham số tự nhiên, kinh tế, xã hội, môi trường... vì thế cũng khác nhau nhất định giữa vùng ĐBSCL và miền Trung. Các tiêu chí ở đây gồm 3 tiêu chí: hiểm họa lũ lụt $(\mathrm{H})$, độ phơi nhiễm $(\mathrm{H})$, tính dễ bị tổn thương $(\mathrm{V})$ với các tham số thuộc các tiêu chí này được xác định là:

(1) Tiêu chí hiểm họa lũ lụt (H) phản ánh tính chất, quy mô, cường độ của tai biến lũ lụt, nó được coi là mối đe dọa trực tiếp đến hệ thống. Các đặc trưng thuộc tiêu chí này có thể là: tần suất lũ, độ sâu ngập lụt, thời gian ngập lụt, diện tích ngập, vận tốc dòng chảy lũ, cường suất lũ. Ở ĐBSCL xét các đặc trưng về lũ cao, lũ trung bình và lũ thấp.

Giá trị các đặc trưng thuộc tiêu chí nguy cơ ngập lụt có thể được xác định bằng các hình thức điều tra hay mô phỏng những trận lũ thực, lũ thiết kế bằng mô hình toán phù hợp. Mô hình áp dụng để mô phỏng lũ có thể là mô hình thủy văn (xác định lượng mưa sinh dòng chảy trên lưu vực), thủy lực 1 chiều (để diễn toán dòng chảy lũ trong sông) hay mô hình 2 chiều (để xác định dòng chảy vượt đê tràn vào khu chứa, vùng đồng bằng)... Ngoài $\mathrm{ra}$, một số đặc trưng khác như tần suất xuất hiện, cường suất đỉnh lũ,... có thể được xác định bằng các phần mềm, phương pháp tính toán thủy văn.

(2) Tiêu chí độ phơi nhiễm (E): đặc trưng cho mức độ ảnh hưởng của hiện trạng bề mặt hệ thống khi tiếp xúc trực tiếp với hiểm họa lũ lụt. Hiện trạng bề mặt hệ thống ở đây là: hiện trạng sử dụng đất, mật độ nhà cửa, mật độ các công trình công cộng, diện tích gieo trồng, vậ nuôi, vùng kinh tế, mật độ dân cư,..

Các tham số thuộc tiêu chí độ phơi nhiễm có thể được xác định bằng các hình thức: khai thác bản đồ, dữ liệu hiện trạng sử dụng đất, bản đồ quy hoạch phát triển kinh tế - xã hội; niên giám thống kê hay điều tra xã hội học,...

(3) Tiêu chí tính dễ bị tổn thưong xã hộ $(V)$ : là mức độ mà ở đó một hệ thống dễ bị ảnh hưởng và khó có thể chống chịu với các tác động tiêu cực của lũ lụt, được xác định thông qua các thành phần tính nhạy và khả năng chống chịu. (i) Tính nhạy: đặc trưng các tính chất về kinh tế, xã hội và môi trường, chúng sẽ phản ứng ra sao trước tai biến lũ lụt. Các biến thuộc thành phần tính nhạy như: dân số, dân tộc, trình độ học vấn, giới tính, độ tuổi, thu nhập, sinh kế, đời sống tinh thần và hiện trạng môi trường, nhiễm mặn, nhiễm phèn...; (ii) Khả năng chống chịu đặc trưng cho khả năng chống đỡ và chịu đựng trước tai biến lũ lụt. Khả năng chống chịu phản ánh sức kháng cự của của người dân, của cộng đồng, của chính quyền và hệ thống tự nhiên trước tai biến lũ lụt. Các biến thuộc thành phần khả năng chống chịu như kinh nghiệm, điều kiện, khả năng chống lũ, công trình phòng, tránh lũ; khả năng dự báo, cảnh báo lũ; sự hỗ trợ của cộng đồng; khả năng tự phục hồi.

Đối với vùng ĐBSCL các tham số thuộc tiêu chí tính dễ bị tổn thương cần được xem xét riêng biệt ở các mức độ lũ khác nhau là cao, thấp và trung bình. Vì ở đây ngoài những ảnh hưởng xấu do lũ cao thì những lợi ích mà lũ lụt mang lại là đáng kể. Hơn nữa đối với lũ thấp, ngoài việc giảm thiểu tác hại của nước cao còn có những bất lợi nhất định do xâm nhập mặn, phèn.

Các tham số thuộc tiêu chí tính dễ bị tổn thương thu nhận được từ điều tra xã hội học 
(phiếu, phỏng vấn, ghi âm, ghi hình...) và thông tin trong niên giám thống kê cấp huyện thuộc lưu vực nghiên cứu.

\subsection{Chuẩn hóa các biến số}

Các biến, thành phần có thứ nguyên khác nhau, vì thế cần chuẩn hóa trước khi tính toán giá trị tính dễ bị tổn thương lũ lụt (1). Trong nghiên cứu này đã sử dụng phương pháp đánh giá chỉ số phát triển con người (HDI) của UNDP (2006) để chuẩn hóa dữ liệu. Các giá trị chuẩn hóa của các biến thu được nằm trong khoảng từ 0 đến 1 và sau bước tính này thiết lập được bộ giá trị các biến đã chuẩn hóa.

$$
x_{i j}=\frac{x_{i j}-\operatorname{Min}_{i}\left\{x_{i j}\right]}{\operatorname{Max}_{i}\left[x_{i j}\right\}-\operatorname{Min}_{i}\left\{x_{i j}\right\}}
$$

trong đó: $x_{i j}$ - giá trị điểm thứ $j$ thuộc biến thứ $i$ đã chuẩn hóa; $X_{\mathrm{ij}}$ - giá trị điểm thứ $j$ thuộc biến thứ $i$ chưa chuẩn hóa; $\operatorname{Max}_{i}\left[X_{i j}\right\}$ - giá trị lớn nhất thuộc biến thứ $i$ chưa chuẩn hóa; $\operatorname{Min}_{i}\left\{X_{i j}\right\}$ - giá trị nhỏ nhất thuộc biến thứ $i$ chưa chuẩn hóa.

\subsection{Xác định trọng số}

Các tiêu chí được thiết lập liên quan đến tai biến lũ lụt được thể hiện qua chỉ số rủi ro lũ lụt tổng hợp. Thực chất, mỗi tiêu chí, thành phần đều có một vai trò nhất định trong việc hình thành mức độ rủi ro của lưu vực. Tùy thuộc vào mục đích đánh giá mà mỗi tác giả có thể coi vai trò của các tiêu chí là ngang bằng hoặc có trọng số đáp ứng yêu cầu của từng bài toán. Ở đây sẽ sử dụng phương pháp xác định trọng số theo phương pháp chuyên gia AHP kết hợp với phương pháp thống kê Iyengar-Sudarshan đã được mô tả chi tiết $[1,5]$.

\subsection{Tính giá trị các tiêu chí}

Tiêu chí hiểm họa lũ lụt $(\mathrm{H})$ : được xác định theo công thức trung bình cộng có trọng số của các tham số: độ sâu ngập, thời gian ngập, diện tích ngập, cường suất lũ ứng với từng tần suất xuất hiện lũ.

Tiêu chí độ phơi nhiễm $(\mathrm{E})$ : được xác định theo công thức trung bình cộng có trọng số của các tham số: mật độ nhà cửa, các công trình công cộng, diện tích lúa, diện tích cây ăn trái, vật nuôi, khu công nghiệp, diện tích nuôi trồng thủy sản, mật độ dân cư, loại đất ứng theo quy hoạch sử dụng đất.

Tiêu chí tính dễ bị tổn thương xã hội $(\mathrm{V})$ : được tính riêng cho 2 thành phần tính nhạy $(\mathrm{S})$ và khả năng chống chịu $(\mathrm{A})$ :

- Tính nhạy (S): được tính là trung bình có trọng số của các tham số: dân số, dân tộc, trình độ học vấn, giới tính, độ tuổi, thu nhập, sinh kế, đời sống tinh thần, hiện trạng môi trường, diện tích nhiễm mặn, diện tích nhiễm phèn.

- Khả năng chống chịu (A) được tính trung bình có trọng số của các tham số: kinh nghiệm chống lũ, điều kiện chống lũ, khả năng chống lũ, công trình phòng lũ, công trình tránh lũ; khả năng dự báo lũ, cảnh báo lũ, sự hỗ trợ của địa phương, khả năng tự phục hồi, khả năng đẩy mặn, khả năng rửa phèn, khả năng làm sạch sâu bọ, khả năng mang phù sa, khả năng mang nguồn lợi thủy sản.

Sau khi $(\mathrm{S})$ và $(\mathrm{A})$ được xác định, tiêu chí (V) được tính theo công thức $\mathrm{V}=\mathrm{S}-\mathrm{A}$, nếu như $\mathrm{A}>\mathrm{S}$ thì $\mathrm{V}$ được lấy $=0$, tức là không bị tổn thương mà ngược lại lũ lụt còn mang đến những lợi ích nhất định cho một vùng, địa phương cụ thể.

\subsection{Xác định chỉ số rủi ro lũ vùng $Đ B S C L$}

Theo ADRC chỉ số rủi ro lũ được xác định là giao của 3 tiêu chí $(\mathrm{H}),(\mathrm{E})$ và $(\mathrm{V})($ Hình 1$)$ [4]. Ở đây nghiên cứu sẽ sử dụng công thức:

$R=H^{*} E^{*} V$, với các giá trị của 3 tiêu chí đã được tính như ở mục 2.5 .

Theo đó để đề xuất các biện pháp nhằm giảm rủi ro lũ là: (i) giảm tính dễ bị tổn thương; (ii) giảm diện tiếp xúc với tác động của hiểm họa như biện pháp di dời nơi ở và tài sản. Rủi ro thiên tai và diện tích bị ảnh hưởng có thể làm giảm nhẹ nếu các biện pháp này được áp dụng đúng.

Sau khi bộ chỉ số rủi ro lũ lụt được tính ứng với từng cấp lũ, ta có thể tổng hợp phân tích hoặc phân tích từng cấp độ riêng biệt cho từng vùng (cell) cụ thể. 


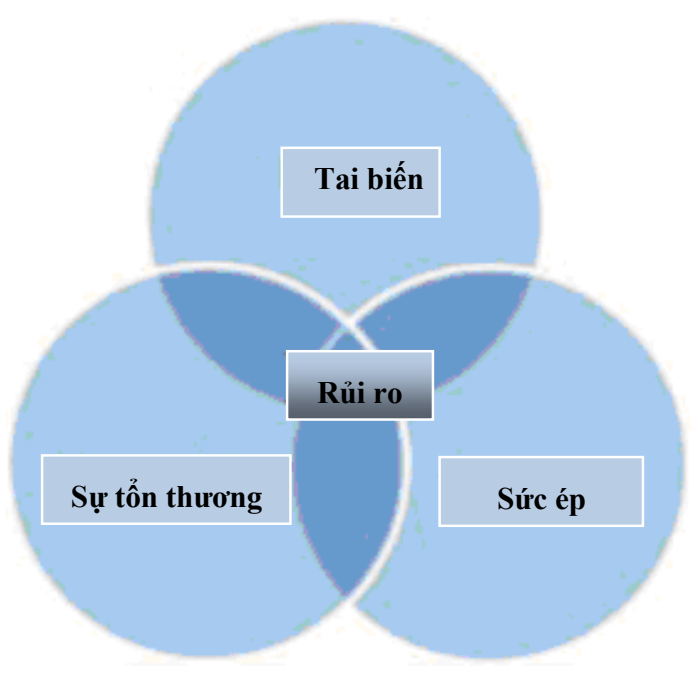

Hình 1. Biểu đồ xác định rủi ro lũ.

Từ bộ chỉ số rủi ro lũ lụt tổng hợp cho các vùng (cell) có thể tiến hành thành lập các bản đồ chuyên đề, các bảng dữ liệu số để người quản lý, người dân có thể tra cứu dễ dàng.

\section{Kết luận}

Như đã phân tích, ĐBSCL là vùng có ý nghĩa quan trọng trong nền kinh tế quốc dân và là vùng có mối quan hệ chặt chẽ với lũ lụt. Lũ lụt không đơn thuần là hiện tượng tự nhiên gây hại cho người dân như những vùng khác mà lũ lụt còn mang lại những lợi ích nhất định cho vùng và tạo nên một vựa lúa của cả nước như ngày nay.

Bộ công cụ là các tiêu chí, thành phần, tham số được xác định dựa trên việc nghiên cứu và am hiểu đặc điểm lũ lụt cũng như mối quan hệ giữa lũ lụt và đời sống kinh tế-xã hội-môi trường của ĐBSCL là cốt lõi của công tác đánh giá rủi ro phục vụ phòng chống tác hại của thiên tai lũ lụt trong đời sống người dân.
Trong khuôn khổ nghiên cứu này bài báo đã thiết lập được phương pháp tính chi tiết cho từng yếu tố cụ thể. Kết quả tính toán và kiểm nghiệm sẽ được trình bày ở nghiên cứu sau.

\section{Lời cảm ơn}

Nghiên cứu này được hoàn thành trong khuôn khổ nghiên cứu của đề tài cấp Bộ Tài nguyên và Môi trường, mã số TNMT.2016.05.15. Các tác giả xin chân thành cảm ơn.

\section{Tài liệu tham khảo}

[1] Cấn Thu Văn (2015), "Nghiên cứu xác lập cơ sở khoa học đánh giá tính dễ bị tổn thương do lũ lụt lưu vực sông Vu Gia - Thu Bồn phục vụ quy hoạch phòng chống thiên tai”, Luận án tiến sĩ ĐHQGHN.

[2] Pilon P J (2003), "Guidelines for reducing flood losses".

(www.un.org/esa/sustdev/puplications/flood_gui delines.pdf)

[3] Nguyen Mai Dang (2010), "Intergrated flood risk assessment for the Day river flood diversion area in the Red river, Vietnam". PhD dissertation of engineering in water engineering and management. AIT 2010

[4] ADRC (2005), "Total diaster risk management good practices", Report. Asian Diaster Reduction Center, Kobe, Japan. Available via Dialog.

[5] Nguyễn Thanh Sơn và nnk (2015), “Đánh giá mức độ tổn thương về kinh tế - xã hội do lũ lụt trên một số lưu vực sông chính ở miền Trung trong bối cảnh biến đổi khí hậu và khai thác công trình thủy điện, thủy lợi", Đề tài cấp nhà nước thuộc chương trình Khoa học và Công nghệ phục vụ chương trình mục tiêu Quốc gia ứng phó với biến đổi khí hậu, mã số BĐKH-19. 


\title{
Research Setting Basic Methods of Flood Risk Assessment in the Mekong Delta
}

\author{
Can Thu Van ${ }^{1}$, Nguyen Thanh Son ${ }^{2}$ \\ ${ }^{1}$ HCMC University of Natural Resources and Environment, \\ 236B Le Van Sy Str., Tan Binh Dist. HCMC \\ ${ }^{2}$ VNU University of Sciences, 334 Nguyen Trai, Thanh Xuan, Hanoi, Vietnam
}

\begin{abstract}
Recently, the most of research on flood risk are identified risk is a function of three components: hazard, exposure and social vulnerability. Flood risk assessment in addition to providing estimates of damage to people and property also proposed measures to reduce disaster risk by considering the capacity of households to adapt and cope when floods event occur. But can not use a method and mitigation measures for different regions, each region has different characteristics floods, economic conditions different social cause vulnerable properties and resistance completely different subject. So, for a particular area is necessary to establish a calculation method most appropriate to ensure the proposed mitigation measures are effective. Especially, floods in the Mekong Delta have different properties compared to other regions in the North or Central of Vietnam was announced in the previous research, so this paper will analyze and establish a risk assessment method by floods suitable for Mekong Delta.
\end{abstract}

Keywords: Floods, flood Risk assesment, Mekong Delta. 